\section{Brazilian manuscripts published in the Dysphagia journal}

Roberto Oliveira Dantas ${ }^{1}$ https://orcid.org/0000-0003-2183-0815

Weslania Viviane Nascimento ${ }^{2}$ https://orcid.org/0000-0003-1267-3475

Universidade de São Paulo, Faculdade de Medicina de Ribeirão Preto, Ribeirão Preto, São Paulo, Brasil.

2 Universidade Autônoma de Barcelona, Laboratório de Fisiologia Gastrointestinal, Hospital de Mataró, Mataró, Espanha.

Conflict of interests: Nonexistent

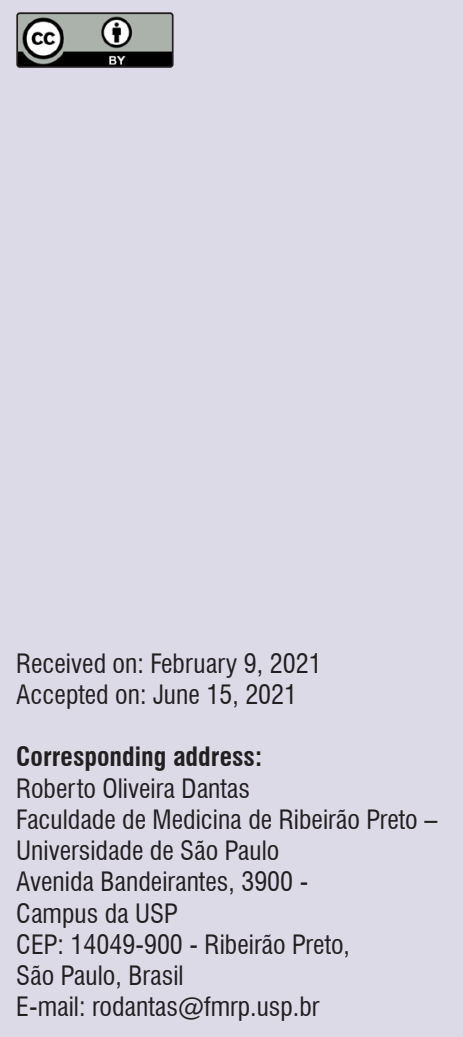

\section{ABSTRACT}

Objective: to survey the Brazilian participation in original and review articles published in the Dysphagia journal.

Methods: original and review articles in volumes 1 to 35 , quantifying all those developed in Brazil, the diseases researched, the places where the investigations were conducted, and the number of citations they received, were analyzed. The categorical variables are presented in relative and absolute frequencies.

Literature Review: a total of 35 Brazilian manuscripts were published. The most researched disease was Parkinson's, followed by Chagas disease, stroke, and the physiology of swallowing. The highest number of publications was carried out at the Universidade de São Paulo, campus at Ribeirão Preto, SP, and the Universidade Federal de São Paulo, capital city. Between 2001 and 2010, 14 manuscripts were published (3.7\% of the journal), and between 2011 and 2020,20 were published $(2.9 \%$ of the journal). By 2019, the manuscripts had received 481 citations - 17 citations per article between 1998 and 2009, and 14, between 2010 and 2019.

Conclusion: Brazilian manuscripts are regularly published in the Dysphagia journal and have a scientific impact. However, there has not been a progressive increase in the number of published articles.

Keywords: Deglutition; Deglutition Disorders; Mouth; Pharynx; Esophagus; Esophageal Diseases 


\section{INTRODUCTION}

Research activity generating new knowledge in the different fields of science has been considered an important indicator of a country's development, regardless of immediate applicability to the population's benefit' ${ }^{1}$.

Dysphagia - meaning swallowing difficulties - is a topic of great interest in the field of health ${ }^{2}$, due to its increasing prevalence, more accurate etiological diagnosis (made possible by the development of videofluoroscopy, functional endoscopy, and high-resolution manometry), and currently available treatment options.

In a country with a limited budget, the diagnosis and treatment costs require attention. Patients with dysphagia cost more than patients without this condition, comparing both groups with similar diseases ${ }^{3-6}$. Besides the higher costs, patients with dysphagia have complications more often as well as longer lengths of stay ${ }^{6}$.

In Brazil, the interest for greater knowledge of dysphagia is noticeable in the growing number of professionals dedicated to its diagnosis and increasing research on dysphagia developed by Brazilians ${ }^{7,8}$.

The first issue of the multidisciplinary, prestigious, and competitive Dysphagia journal was published in 1986. It is the first - and so far, the only - international journal exclusively focused on the field of dysphagia, "dedicated to advancing the art and science of deglutology". Moreover, it is the official journal of the Dysphagia Research Society (DRS), the European Society for Swallowing Disorders (ESSD), and the Japanese Society of Dysphagia Rehabilitation (JSDR). At first, up until 2013, it published quarterly issues (four a year), and from 2014, it started publishing bimonthly (six issues a year).

In 2013, the journal published a survey of the number of accepted abstracts presented in the conferences of the Dysphagia Research Society between 2001 and 20117. There were 80 Brazilian papers presented, inferior only to the United States $(n=420)$, Japan ( $n=$ 216 ), and Europe (all the countries, $n=83$ ), increasing from zero in 2001 and 2002 to 19 in 2010 and 13 in 2011. Such results point to the growing participation of Brazilians in research on dysphagia over those 10 years.

The objective of this investigation was to survey Brazilian participation in original and review articles published in the Dysphagia journal. The hypothesis is that the number of both manuscripts published as a result of research conducted in Brazil and citations of such studies increased over the years.

\section{METHODS}

\section{Inclusion and exclusion criteria}

The titles and authors of the manuscripts published as original and review articles from volume 1 (19861987) to 35 (2020) of the Dysphagia journal (ISSN: 1432-0460) were analyzed. All the original and review articles were evaluated. Editorials, case publications, abstracts, letters to the editor, and comments on books or other publications were not included in this survey.

Papers carried out by Brazilians at some Brazilian institution, either with or without the participation of foreign researchers were considered Brazilian. As this investigation included neither humans nor animals, the research was not subject to approval by the institution's Ethics Committee.

Data analysis

After being identified, Brazilian articles were evaluated regarding the number and percentage of the total publications in each set of five volumes, which disease the research was focused on, and where it was carried out. Also, on December 30, 2020, the number of citations of Brazilian articles as reported in the journal's website, encompassing the articles published up until volume 34 (2019), was surveyed.

On that same day, December 30, 2020, the number of manuscripts accepted for publication that were listed on the journal's website as online first articles, were surveyed.

The categorical variables are presented in relative and absolute frequencies.

\section{LITERATURE REVIEW}

Altogether, 1,567 manuscripts conducted in different parts of the world were published in the Dysphagia journal from volume 1 to 35 .

Of the total, 35 had been carried out in Brazil, corresponding to $2.2 \%$. The first Brazilian paper was published in 1998 (volume 13). The highest number of Brazilian publications ( $n=5,10.6 \%$ of the whole volume) occurred in 2008 (volume 23).

The number of Brazilian publications (Figure 1A) and its percentage of the total number of manuscripts published (Figure 1B) reveal that the proportion in the 2001-2010 decade (volumes 16 to $25 ; n=14 ; 3.7 \%$ of the total) tended to remain steady in the 2011-2020 decade (volume 26 to $35 ; n=20 ; 2.9 \%$ of the total). 

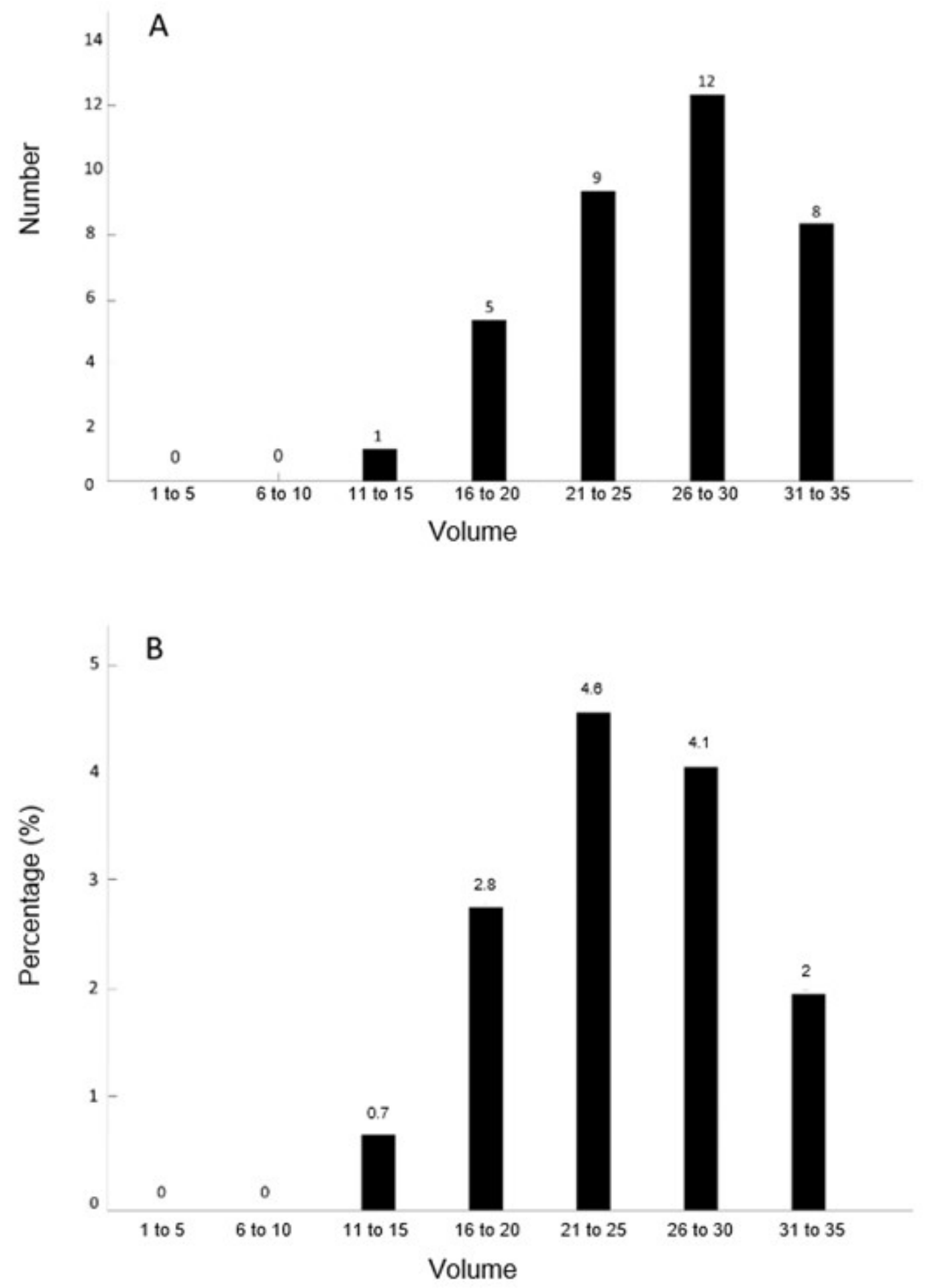

Figure 1. Brazilian papers published in the Dysphagia journal from volume 1 (1986-1987) to 35 (2020), in number of publications (A) and percentage of the total number of publications (B), in each set of five volumes 
The diseases researched by Brazilians are shown in Table 1. The ones that stood out were Parkinson's disease, Chagas disease, stroke, swallowing in healthy people (physiology of swallowing), head and neck cancer, and laryngectomized patients, with 22 (62.8\%) of the manuscripts.

Another 13 (37.2\%) papers approached different topics: effects of habitual cocaine use on swallowing, surgical intervention in cases of aspiration, myotonic dystrophy, obstructive sleep apnea syndrome, esophageal $\mathrm{pH}$ measurement, esophageal diverticulum, nutcracker esophagus, swallowing in children with postprandial vomiting, effects of aging, histology of the upper esophageal sphincter, thyroidectomy, vagal paralysis, and use of botulinum toxin in the treatment of dysphagia.

Regarding the swallowing phases, 28 (80\%) studies evaluated the oral and pharyngeal phases, while seven (20\%) evaluated the esophageal phase.

The places where the investigations were conducted are shown in Table 2. There was a significant predominance of institutions from the Southeast Region of Brazil $(n=29 ; 83 \%)$.

Table 1. Diseases investigated by Brazilian researchers and published in the Dysphagia journal from volume 1 to 35 (1986-2020)

\begin{tabular}{lcc}
\hline & NUMBER & PERCENTAGE (\%) \\
\hline Parkinson's disease & 5 & 14.3 \\
Chagas disease & 4 & 11.4 \\
Stroke & 4 & 11.4 \\
Physiology of swallowing & 4 & 11.4 \\
Head and neck cancer & 3 & 8.6 \\
Laryngectomy & 2 & 5.7 \\
Others & 13 & 37.2 \\
\hline TOTAL & 35 & 100 \\
\hline
\end{tabular}

Table 2. Places where research was carried out by Brazilians who published in the Dysphagia journal from volume 1 to 35 (1986-2020)

\begin{tabular}{lcc}
\hline & NUMBER & PERCENTAGE (\%) \\
\hline Universidade de São Paulo - Ribeirão Preto - SP & 13 & 37.1 \\
Universidade Federal de São Paulo - SP & 6 & 17.1 \\
Universidade Federal de Pernambuco - PE & 3 & 8.6 \\
Universidade de São Paulo - São Paulo - SP & 3 & 8.6 \\
Universidade Federal do Rio de Janeiro - RJ & 2 & 5.7 \\
AC Camargo Cancer Center - São Paulo - SP & 2 & 5.7 \\
Universidade Estadual Paulista - Marília - SP & 2 & 5.7 \\
Universidade Federal da Bahia - BA & 2 & 5.7 \\
Universidade Federal de Ciências da Saúde - Porto Alegre - RS & 1 & 2.9 \\
Santa Casa de São Paulo - SP & 1 & 2.9 \\
\hline TOTAL & 35 & 100 \\
\hline
\end{tabular}

Altogether, these publications were cited 481 times in the literature (Web of Science), ranging from 1 to 38 (median of 14 and mean of 16). The most cited papers $^{9-19}$ are presented in Table 3 . The manuscripts published between 1998 and 2009 were cited 254 times (mean of 17 citations per article), and those published between 2010 and 2019 were cited 227 times (mean of 14 citations per article). 
Table 3. Brazilian manuscripts in the Dysphagia journal (volumes 1 to 35) with the most citations by December 30, 2020

\begin{tabular}{|c|c|c|c|c|}
\hline First author & Volume (n) & Page & Year & Citations \\
\hline Onofri SMM ${ }^{9}$ & $29(2)$ & 256 & 2014 & 38 \\
\hline Dantas R010 & $24(3)$ & 280 & 2009 & 32 \\
\hline Bandeira AKC ${ }^{11}$ & $23(2)$ & 183 & 2008 & 32 \\
\hline Coriolano MGWS ${ }^{12}$ & 27 (4) & 550 & 2012 & 24 \\
\hline Nascimento FAP ${ }^{13}$ & $21(3)$ & 198 & 2006 & 23 \\
\hline Argolo N ${ }^{14}$ & $30(6)$ & 751 & 2015 & 21 \\
\hline Carneiro D ${ }^{15}$ & $29(5)$ & 578 & 2014 & 21 \\
\hline Silva ACV ${ }^{16}$ & $23(2)$ & 165 & 2008 & 21 \\
\hline Meneghelli UG'17 & $20(1)$ & 40 & 2005 & 20 \\
\hline Ercolin B ${ }^{18}$ & $28(3)$ & 446 & 2013 & 20 \\
\hline Belo LR ${ }^{19}$ & $29(4)$ & 419 & 2014 & 18 \\
\hline
\end{tabular}

Caption: $\mathrm{n}$ - number

On December 30, 2020, there were 78 online first articles, of which five $(6.4 \%)$ resulted from investigations carried out in Brazil.

The prevalence of dysphagia in the population has been increasing, especially because of the growing proportion of older adults ${ }^{20}$ and the survival of premature infants ${ }^{21}$.

Dysphagia can occur at any age and requires multiprofessional attention. It significantly impairs the patients' quality of life ${ }^{22}$, it has a high diagnostic and treatment $\operatorname{cost}^{3-6}$, and oftentimes its prognostic is not $\operatorname{good}^{23}$.

The scientific advancements in the methods to investigate swallowing changes led to a significant increase in investigations of dysphagia over the last 30 years. This reflected on the number of manuscripts published in Dysphagia: 352 in volumes 1 to 10 (19861995) and 691 in volumes 26 to 35 (2011-2020) - a 96\% increase.

The radiological, manometric, electromyographic, scintigraphic, and endoscopic methods greatly impacted the knowledge of the physiology of swallowing and dysphagia. Multidisciplinary teams that study the physiopathology, diagnosis, and treatment of dysphagia are important assets, which should be present in all the states of the country, also considering the possibility of regional differences in the prevalence of diseases that cause dysphagia.

Surveying only the Dysphagia journal, it was observed that since 2005 there has been a relatively stable proportion of Brazilian papers published in it. Determining whether this number is high or low depends on appraising the barriers overcome to reach such balance as well as the growth potential.
Conducting research is not an easy task, as it demands time, dedication, and resources. An analysis approaching the Dysphagia journal alone does not allow for definitive conclusions about the Brazilian research on dysphagia because there are manuscripts published in other journals as well, some of which are more competitive and have a greater impact than Dysphagia.

To increase the number of publications in this and other journals the assessment methods, dedication to research, and writing of the articles need to improve. Language is known to be a limitation that sometimes hinders the acceptance of quality manuscripts. Mastering a language takes time, to which an alternative is hiring specialized translation companies - which on the other hand increases the publication costs. Nonetheless, these can ensure a better understanding on the part of journal reviewers and editors.

Brazil offers excellent postgraduate programs. Writing and publishing manuscripts should be the goal of all postgraduate students, which might significantly increase the impact of Brazilian research.

The Brazilian papers researched 19 diseases. Such diversity must be due to the different investigation groups and fields of interest, which points to the importance of having research conducted in the various regions of the country, focusing on regional issues. Diversity is a positive fact in research groups.

It was observed that the vast majority of the manuscripts were developed in the Southeast Region of the country (83\%). This result is similar to the one obtained in a survey of research on dysphagia published in Brazil (70\% from the Southeast), which 
included only manuscripts on oropharyngeal dysphagia in older adults and found 43 articles between 1995 and 2015. In the same period, 27 Brazilian papers were published in Dysphagia, encompassing all ages and both oropharyngeal and esophageal dysphagia.

One of the methods to assess the impact of a publication is the number of citations it receives. The Brazilian manuscripts received 481 citations, a median of 14 per article. The most cited ones include the three carried out at the Universidade Federal de Pernambuco (Federal University of Pernambuco) 12,15,19, three conducted at the Universidade de São Paulo em Ribeirão Preto (University of São Paulo in Ribeirão Preto, SP) ${ }^{10,16,17}$, and the investigations on Parkinson's disease ${ }^{12,14,15,19}$. The most cited article resulted from research conducted at the Universidade Estadual Paulista em Marília (São Paulo State University in Marília, SP) ${ }^{9}$.

The manuscripts published between 1998 and 2009 received more citations (16.9 per manuscript) than those published between 2010 and 2019 (12.8 per manuscript). The difference is small and must be due to the longer time the older articles have been available for reading and citation.

This paper has limitations, as it surveyed only one important and specialized journal. However, dysphagia is a multidisciplinary field, and manuscripts on this topic may be published in journals specialized in speech-language-hearing pathology, neurology, head and neck surgery, otorhinolaryngology, gastroenterology, nutrition, pediatrics, physiology, geriatrics, rehabilitation, medical engineering, and other fields of knowledge. These are specialized journals, and manuscripts on dysphagia are not always within the editors' field of interest. There are no similar papers to which compare this one.

\section{CONCLUSION}

A total of 35 Brazilian papers were published from volume 1 (1986-1987) to 35 (2020) of the Dysphagia journal, which represents $2.2 \%$ of all the original and review articles published there. Parkinson's disease was the most investigated one. By December 30, 2020, these manuscripts had been cited 481 times in the literature, an average of 14 citations per manuscript. Since 2000, there has been no progressive increase in the number of Brazilian manuscripts published in Dysphagia journal. Nevertheless, they are published in a regular proportion and have a scientific impact.

\section{REFERENCES}

1. Antunes EP, Teixeira YBS, Ferreira LH. A importância da atividade científica: concepções dos produtores de conhecimento químico de uma universidade pública. Cienc Educ. 2020;26:e20044.

2. Santoro PP. Disfagia orofaríngea: panorama atual, epidemiologia, opções terapêuticas e perspectivas futuras. Rev. CEFAC. 2008;10(2):Editorial II.

3. Westmark S, Melgaard D, Rathemeier LO, Ehlers $\mathrm{LH}$. The cost of dysphagia in geriatric patients. Clinicoecon Outcomes Res. 2018;10:321-6.

4. Patel DA, Krishnaswami S, Steger E, Conover E, Vaezi MF, Ciucci MR et al. Economic and survival burden of dysphagia among inpatients in the United States. Dis Esophagus. 2018;31(1):1-7.

5. Allen J, Greene M, Sabido I, Stretton M, Miles A. Economic costs of dysphagia among hospitalized patients. Laryngoscope. 2020;130(4):974-9.

6. Cohen SM, Lekan D, Risoli Junior T, Lee HJ, Misono S, Whitson HE et al. Association between dysphagia and inpatient outcomes across frailty level among patients $\geq 50$ years of age. Dysphagia. 2020;35(5):787-97.

7. Plowman EK, Mehdizadeh O, Leder SB, Martino $\mathrm{R}$, Belafski PC. A bibliometric review of published abstract presented at the Dysphagia Research Society: 2001-2011. Dysphagia. 2013;28(2):123-30.

8. Rodrigues LKV, Pernambuco L. Scientific production on oropharyngeal dysphagia in elderly in Brazilian journals: a bibliometric analysis. Disturb. Comum. 2017;29(3):529-38.

9. Onofri SMM, Cola PC, Berti LC, Silva RG, Dantas RO. Correlation between laryngeal sensitivity and penetration/aspiration after stroke. Dysphagia. 2014;29(2):256-61.

10. Dantas RO, Cassiani RA, Santos CM, Gonzaga GC, Alves LMT, Mazin SC. Effect of gender on swallow duration assessed by videofluoroscopy. Dysphagia. 2009;24(3):280-4.

11. Bandeira AKC, Azevedo EHM, Vartanian JG, Nishimoto IN, Kowalski LP, Carrara-de-Angelis E. Quality of life related to swallowing after tongue cancer treatment. Dysphagia. 2008;23(2):183-92.

12. Coriolano MGWS, Belo LR, Carneiro D, Asano AG, Oliveira PJAL, Silva DM et al. Swallowing in patients with Parkinson's disease: a surface electromyographic study. Dysphagia. 2012;27(4):550-5. 
13. Nascimento FAP, Lemme EMO, Costa MMB. Esophageal diverticula: pathogenesis, clinical aspects, and natural history. Dysphagia. 2006;21(3):198-205.

14. Argolo N, Sampaio M, Pinho P, Melo A, Nóbrega AC. Videofluoroscopic predictors of penetration-aspiration in Parkinson's disease patients. Dysphagia. 2015;30(6):751-8.

15. Carneiro D, Coriolano MGWS, Belo LR, Rabelo ARM, Asano AG, Lins OG. Quality of life related to swallowing in Parkinson's disease. Dysphagia. 2014;29(5):578-82.

16. Silva ACV, Fabio SRC, Dantas RO. A scintigraphic study of oral, pharyngeal and esophageal transit in patients with stroke. Dysphagia. 2008;23(2):165-71.

17. Meneghelli UG, Peria FM, Darezzo FMR, Almeida $\mathrm{FH}$, Rodrigues CM, Aprile LRO et al. Clinical, radiographic and manometric evolution of esophageal involvement by Chagas' disease. Dysphagia. 2005;20(1):40-5.

18. Ercolin B, Sassi FC, Mangilli LD, Mendonça LIZ, Limongi SCO, Andrade CRF. Oral motor movements and swallowing in patients with myotonic dystrophy type 1. Dysphagia. 2013;28(3):445-54.

19. Belo LR, Gomes NAC, Coriolano MGWS, Souza ES, Moura DAA, Asano AG et al. The relationship between limit of dysphagia and average volume per swallow in patients with Parkinson's disease. Dysphagia. 2014;29(4):419-24.

20. Bhattacharyya $N$. The prevalence of dysphagia among adults in the United States. Otolaryngol Head Neck Sur. 2014;151(5):765-9.

21. LaTuga MS, Mittelstaedt G, Moon JY, Kim M, Murray-Keane L, Si W et al. Clinical characteristics of premature infants who orally feed on continuous positive airway pressure. Early Hum Dev. 2019;139:104833.

22. Kim DY, Park HS, Park SW, Kim JH. The impact of dysphagia on quality of life in stroke patients. Medicine. 2020;99(34):e21795.

23. Sunata K, Terai H, Seki H, Mitsuhashi M, Kagoshima Y, Nakayama $S$ et al. Analysis of clinical outcomes in elderly patients with impaired swallowing function. PLoS One. 2020;15(9):e0239440. 